\title{
Interpreting the rising incidence of meningococcal disease in Belgium: the contribution of molecular typing
}

\author{
M. VAN LOOVEREN, D. A. CAUGANT*, S. CHAPELLE, F. CARION† and H. GOOSSENS
}

Department of Medical Microbiology, University Hospital Antwerp, UIA, Antwerp, Belgium, *World Health Organization Collaborating Centre for Reference and Research on Meningococci, National Institute of Public Health, Oslo, Norway and †Department of Bacteriology, Scientific Institute for Public Health-Louis Pasteur, Brussels, Belgium

\begin{abstract}
During a period of increasing meningococcal disease incidence in Belgium, all 538 serogroup $B$ and all 87 serogroup $C$ strains isolated between 1996 and 1998 were investigated by PCR with the arbitrary primer D8635, which is able to identify lineage III strains. In all, 399 strains (64\%) were attributed to lineage III on the basis of PCRbased typing. Since their introduction in the Belgian population in the early 1990s, lineage III strains have become increasingly variable in phenotype. Currently, they are represented by strains belonging to 38 different phenotypes, of which 25 were not found in the period 1990-1995. The 87 serogroup $C$ strains were further investigated by pulsed-field gel electrophoresis (PFGE), and a subset of 30 strains was also investigated by multilocus sequence typing (MLST). Strains of phenotype C:2b:P1.5,2, which currently constitute the majority of the serogroup $C$ strains, were demonstrated to belong to cluster A4. Comparison of the discriminatory ability of D8635-primed PCR, PFGE and MLST revealed that D8635-primed PCR was the least discriminatory method and PFGE the most discriminatory method. However, the MLST data were more readily interpreted than the PFGE fingerprint patterns and can be compared easily with data obtained in other studies. In conclusion, the ongoing increase of meningococcal disease in Belgium could be attributed not only to the further expansion of lineage III, but also to the introduction of $C: 2 \mathrm{~b}: P 1.5,2$ strains of cluster $A 4$ in to the Belgian population.
\end{abstract}

\section{Introduction}

In Belgium the incidence of meningococcal disease increased from 0.8 cases per $10^{5}$ inhabitants in 1990 to 2.24 per $10^{5}$ inhabitants in 1998 . In particular, the incidence in the age group 15-19 years increased to 7.2 per $10^{5}$ inhabitants in 1998 . Investigation of a set of 420 clinical strains isolated during the period 19901995 revealed that this increase was due to the introduction of strains of lineage III in the susceptible Belgian population since the early 1990s [1]. Strains of lineage III were first encountered in the Netherlands and have caused disease there since the early 1980s [2]. The epidemic clone could be identified by oligonucleotide D8635-primed PCR, and encompassed mainly the

Received 15 Jan. 2001; revised manuscript accepted 11 April 2001.

Corresponding author: Dr M. Van Looveren (e-mail: vloovere@uia.ua.ac.be). phenotypes B:4:P1.4 and B:non-typable (NT):P1.4, although strains of several other phenotypes were also encountered $[1,3]$. Strains with phenotypes B:4:P1.4 and B:NT:P1.4 currently cause $39.7 \%$ of the cases of meningococcal disease in Belgium.

From 1997 onwards, the proportion of serogroup B strains decreased, while that of serogroup C strains increased in Belgium. In 1996, serogroup C constituted $7.0 \%$ of the strains and in 1998 it represented $20.8 \%$. The subtype P1.5,2 sharply increased from 7\% in 1996 to $48 \%$ in 1998 . Strains of phenotype C:2b:P1.5,2 currently constitute the majority of the serogroup $\mathrm{C}$ strains $(28 \%)$, followed by C:2a:P1.5,2 (15\%).

The aim of the present study was to investigate the molecular epidemiology of meningococcal disease in Belgium from 1996 to 1998 by the use of several genotyping methods, including arbitrarily primed PCR, pulsed-field gel electrophoresis (PFGE) and multilocus sequence typing (MLST). A secondary aim was to 
compare the discriminatory ability of the different genotyping methods for serogroup $\mathrm{C}$ meningococci.

\section{Materials and methods}

\section{Bacterial strains}

Between Jan. 1996 and Dec. 1998, 685 strains of Neisseria meningitidis isolated from patients with meningococcal disease were received at the Belgian Meningococcal Reference Centre. The serogroup was determined, and serotyping and subtyping were performed as described previously [3].

\section{PCR-based typing}

A subset of 625 strains, comprising all 538 serogroup B strains and all 87 serogroup C strains, was investigated by D8635-primed PCR. DNA extraction and PCR with the arbitrary primer D8635 were performed as described previously [1].

\section{PFGE-based typing}

All 87 serogroup $C$ strains were further investigated by PFGE with the restriction enzyme SpeI. PFGE was performed as described previously [1].

\section{MLST}

The MLST procedure was applied to a subset of 30 serogroup $\mathrm{C}$ strains, representing the different PCR subtypes. The sequences of fragments from the $a b c Z$ (putative $\mathrm{ABC}$ transporter), $a d k$ (adenylate kinase), aroE (shikimate dehydrogenase), fumC (fumarate hydratase), gdh (glucose-6-phosphate dehydrogenase), $p d h C$ (pyruvate dehydrogenase subunit) and pgm (phosphoglucomutase) genes were determined as described on the MLST website (http://mlst.zoo.ox.ac.uk) and compared to the sequences of known alleles. A novel allele at the $\operatorname{aro} E$ locus was assigned the allelic designation aroE120. New combinations of the seven alleles were reported to the MLST website and were assigned the designations ST1025-ST1035.

\section{Results}

\section{PCR-based typing}

A total of 399 strains (64\%) exhibited the epidemic pattern 2723 or a very similar pattern (Table 1), associated with lineage III. A previous study [1] demonstrated that the epidemic clone of lineage III consisted of strains belonging to 16 different phenotypes (B:4:P1.4; B:NT:P1.4; B:4:P1.13; B:NT:NST; B:1:P1.4; B:NT:P1.5,2; B:4:P1.1,7; B:14:P1.4; B:14:P1.15; B:4:P1.6; B:4:P1.7; B:NT:P1.7; B:4:NST; $\mathrm{C}: 4: \mathrm{P} 1.4$ and NG:NT:NST). In the present investigation, all these phenotypes except three (B:4:P1.6; B:NT:P1.7; and NG:NT:NST) were found again.
However, the present study also found another 25 serotype:serosubtype combinations with the epidemic pattern 2723. All these additional combinations were of serogroup B (Table 1). Serotypes B:4:P1.4 and B:NT:P1.4 constituted $72.7 \%$ of the pattern 2723 strains. The remaining $27.3 \%$ of the pattern 2723 strains had other phenotypes.

Amongst the 87 serogroup $\mathrm{C}$ strains, 14 different pattern types $(\mathrm{A}-\mathrm{N})$ could be distinguished, of which two (B and $\mathrm{C}$ ) comprised the majority of the strains. Nine pattern types $(\mathrm{F}-\mathrm{N})$ were represented by a single strain. All C:2b:P1.5,2 strains belonged to pattern type C (Table 2).

\section{PFGE-based typing}

Among the serogroup $C$ strains the same clusters were found as with PCR-based typing, but PFGE was more discriminatory. The 38 strains of PCR pattern B showed 25 PFGE patterns, each represented by oneto-three strains. Among the 25 isolates with PCR pattern C, 8 PFGE patterns were seen. All strains with phenotype $\mathrm{C}: 2 \mathrm{~b}: \mathrm{P} 1.7,1$ had an indistinguishable PFGE pattern and $13(81 \%)$ of the 16 strains with phenotype $\mathrm{C}: 2 \mathrm{~b}: \mathrm{P} 1.5,2$ also had an indistinguishable PFGE pattern. The remaining three $\mathrm{C}: 2 \mathrm{~b}: \mathrm{P} 1.5,2$ strains were, respectively, closely related (two strains) and possibly related (one) [4] to the other $13 \mathrm{C}: 2 \mathrm{~b}: \mathrm{P} 1.5,2$ strains. The single $C: 2 \mathrm{~b}: \mathrm{P} 1.2$ strain of PCR pattern $\mathrm{C}$ had the same PFGE pattern as the C:2b:P1.5,2 strains. For PCR pattern $D$, six of eight C:NT:NST strains and the one $\mathrm{C}: 4: \mathrm{P} 1.7$ strain also showed an indistinguishable pattern. The three PCR pattern E strains each showed a different PFGE pattern. The strains belonging to PCR pattern $\mathrm{A}$ and $\mathrm{PCR}$ patterns $\mathrm{F}-\mathrm{N}$ all had different PFGE patterns.

\section{$M L S T$}

The 30 strains were assigned to 21 sequence types (ST), of which 11 were new (designated ST1025ST1035) (Table 3). The C:4:P1.4 strain of PCR pattern A (Table 2) belonged to ST42, which represents lineage III. The other PCR pattern A strain had a new ST (ST1028) which differed from ST42 at the $a b c Z$ and fumC loci. The C:2a:NST; C:2b:P1.5; $\mathrm{C}: 2 \mathrm{~b}: \mathrm{NST}$ and $\mathrm{C}: \mathrm{NT}: \mathrm{P} 1.2,5$ strains belonging to PCR pattern B were all ST11 (Table 2), the ST most commonly associated with strains of the ET-37 complex. PFGE of the four ST11 strains revealed three different PFGE patterns. The C:2a:NST; C:2a:P1.5 and $\mathrm{C}: 2 \mathrm{a}: \mathrm{P} 1.5,2$ strains of PCR pattern B belonged to three novel STs labelled ST1025, ST1026 and ST1027, each differing from ST11 at a single locus (fumC or pgm). The pattern C strains belonged to ST153 or ST66, both representing the A4 cluster. The two ST153 strains showed a different PFGE pattern. Among the three ST66 strains, two PFGE patterns could be distinguished. 
Table 1. Distribution of pattern 2723, as determined by D8635-PCR, among 625 N. meningitidis strains isolated in Belgium between 1996 and 1998

\begin{tabular}{|c|c|c|c|c|c|}
\hline \multirow[b]{3}{*}{$\begin{array}{l}\text { Strain and } \\
\text { phenotype }^{*}\end{array}$} & \multicolumn{5}{|c|}{ Number of strains with D8635-primed PCR DNA amplification pattern } \\
\hline & \multicolumn{4}{|c|}{ pattern 2723} & \multirow[b]{2}{*}{ other patterns } \\
\hline & $\begin{array}{c}\text { pattern } \\
2723\end{array}$ & $\begin{array}{l}\text { absence of } \\
\text { one band }\end{array}$ & $\begin{array}{l}\text { presence of } \\
\text { an additional } \\
\text { band }\end{array}$ & $\begin{array}{l}\text { difference in } \\
\text { density of } \\
\text { one band }\end{array}$ & \\
\hline $\mathrm{B}: 1: \mathrm{P} 1.4$ & 4 & 0 & 1 & 1 & 0 \\
\hline $\mathrm{B}: 1: \mathrm{P} 1.9$ & 1 & 0 & 0 & 0 & 0 \\
\hline $\mathrm{B}: 4: \mathrm{P} 1.1$ & 2 & 0 & 0 & 0 & 2 \\
\hline $\mathrm{B}: 4: \mathrm{P} 1.1,7$ & 8 & 2 & 0 & 0 & 3 \\
\hline $\mathrm{B}: 4: \mathrm{P} 1.2,5$ & 2 & 0 & 0 & 0 & 12 \\
\hline B:4:P1.4 & 237 & 5 & 4 & 23 & 3 \\
\hline $\mathrm{B}: 4: \mathrm{P} 1.4,7$ & 6 & 0 & 0 & 1 & 1 \\
\hline$B: 4: P 1.5$ & 1 & 0 & 0 & 0 & 0 \\
\hline $\mathrm{B}: 4: \mathrm{P} 1.7$ & 4 & 0 & 1 & 0 & 2 \\
\hline B:4:P1.7,14 & 1 & 0 & 0 & 0 & 0 \\
\hline B:4:P1.9 & 1 & 0 & 0 & 0 & 0 \\
\hline $\mathrm{B}: 4: \mathrm{P} 1.12,13$ & 1 & 0 & 0 & 0 & 0 \\
\hline $\mathrm{B}: 4: \mathrm{P} 1.13$ & 11 & 1 & 2 & 1 & 2 \\
\hline B:4:P1.15 & 4 & 0 & 0 & 0 & 20 \\
\hline B:4:P1.16 & 2 & 0 & 0 & 0 & 1 \\
\hline $\mathrm{B}: 4,21: \mathrm{P} 1.4$ & 0 & 0 & 0 & 1 & 0 \\
\hline B:4:NST & 9 & 1 & 2 & 0 & 2 \\
\hline $\mathrm{B}: 14: \mathrm{P} 1.1,7$ & 1 & 2 & 0 & 0 & 1 \\
\hline $\mathrm{B}: 14: \mathrm{P} 1.2,5$ & 1 & 0 & 0 & 0 & 0 \\
\hline B:14:P1.4 & 1 & 0 & 0 & 0 & 3 \\
\hline $\mathrm{B}: 14: \mathrm{P} 1.5$ & 3 & 0 & 0 & 0 & 1 \\
\hline B:14:P1.13 & 1 & 1 & 0 & 0 & 2 \\
\hline B:14:P1.15 & 4 & 0 & 1 & 0 & 0 \\
\hline B:14:P1.16 & 1 & 0 & 0 & 0 & 0 \\
\hline B:14:NST & 1 & 0 & 0 & 0 & 0 \\
\hline $\mathrm{B}: 15: \mathrm{P} 1.4$ & 3 & 0 & 0 & 0 & 0 \\
\hline $\mathrm{B}: 15: \mathrm{P} 1.4,7$ & 1 & 0 & 0 & 0 & 0 \\
\hline $\mathrm{B}: 21: \mathrm{P} 1.4$ & 0 & 0 & 0 & 1 & 0 \\
\hline B:NT:P1.1 & 2 & 0 & 0 & 0 & 0 \\
\hline B:NT:P1.1,7 & 2 & 0 & 0 & 0 & 2 \\
\hline B:NT:P1.2,5 & 2 & 0 & 0 & 0 & 0 \\
\hline B:NT:P1.4 & 18 & 0 & 0 & 3 & 2 \\
\hline B:NT:P1.4,7 & 1 & 0 & 0 & 0 & 0 \\
\hline B:NT:P1.6 & 0 & 0 & 0 & 1 & 2 \\
\hline B:NT:P1.9 & 0 & 0 & 0 & 1 & 2 \\
\hline B:NT:P1.13 & 1 & 0 & 0 & 0 & 0 \\
\hline B:NT:NST & 4 & 0 & 1 & 0 & 4 \\
\hline $\mathrm{C}: 4: \mathrm{P} 1.4$ & 1 & 0 & 0 & 0 & 1 \\
\hline Others & 0 & 0 & 0 & 0 & 158 \\
\hline Total & 342 & 12 & 12 & 33 & 226 \\
\hline
\end{tabular}

${ }^{*}$ NG, non-groupable; NT, non-serotypable; NST, non-sero-subtypable.

Strains of PCR pattern D belonged to two novel STs labelled ST1031 and ST1032, differing from one another solely at the aroE locus. The three ST1031 isolates presented two different PFGE patterns. One of the ST1031 isolates (C:NT:NST) showed the same PFGE pattern as the ST1032 isolate (C:NT:NST).

\section{Discussion}

Since 1990, the incidence of meningococcal disease in Belgium has increased almost three-fold. This increase is mainly due to genotypically related serogroup B isolates, first identified in the Netherlands [2] and designated lineage III strains [1]. Recently, lineage III strains have been isolated in many other western European countries, including Iceland, Finland, Norway, the UK, Greece and Austria. However, they are not restricted to Europe. Recently, a strain belonging to lineage III was found in Chile, and in New Zealand lineage III strains are causing an ongoing epidemic [5]. As lineage III strains are particularly associated with an increased incidence of disease, this lineage is termed a 'hyper-virulent lineage' [6].

Lineage III encompasses mainly the phenotypes B:4:P1.4 and B:NT:P1.4. The proportion of these phenotypes further increased from $36.0 \%$ in 1995 [3] to $39.7 \%$ in 1998 . However, lineage III is not confined to these phenotypes only, as was demonstrated in an earlier study [1]. In the present investigation B:4:P1.4 and B:NT:P1.4 strains constituted $72.7 \%$ of the pattern 2723 strains. The remaining $27.3 \%$ belonged to 36 different phenotypes. Of these, 25 phenotypes were not encountered in the previous years [1]. Thus, lineage III strains show rapid evolutionary changes in their 
Table 2. D8635-primed PCR for all 87 serogroup C strains isolated in Belgium during 1996-1998, and MLST of a selection of 30 serogroup C strains representing the different PCR subtypes

\begin{tabular}{|c|c|c|}
\hline $\begin{array}{l}\text { Type D8635-primed PCR } \\
\text { (number of strains) }\end{array}$ & Phenotype (n) & Sequence type (n) \\
\hline \multirow[t]{2}{*}{$\overline{A^{*}(2)}$} & C:4:P1.4 (1) & $42(1)$ \\
\hline & C:NT:NST (1) & $1028(1)$ \\
\hline \multirow[t]{6}{*}{ B (38) } & C:2a:NST (7) & 1025 (1) and 11 (1) \\
\hline & C:2a:P1.5 (14) & 1027 (1) \\
\hline & $\mathrm{C}: 2 \mathrm{a}: \mathrm{P} 1.5,2$ (11) & $1026(1)$ \\
\hline & $\mathrm{C}: 2 \mathrm{~b}: \mathrm{P} 1.5$ & $11(1)$ \\
\hline & C:2b:NST (1) & $11(1)$ \\
\hline & C:NT:P1.2,5 (2) & $11(1)$ \\
\hline \multirow[t]{5}{*}{ C (25) } & C:2b:NST (1) & $153(1)$ \\
\hline & $\mathrm{C}: 2 \mathrm{~b}: \mathrm{P} 1.7,1$ (6) & $66(1)$ \\
\hline & $\mathrm{C}: 2 \mathrm{~b}: \mathrm{P} 1.2(1)$ & $66(1)$ \\
\hline & $\mathrm{C}: 2 \mathrm{~b}: \mathrm{P} 1.5,2$ (16) & $66(1)$ \\
\hline & $\mathrm{C}: 2 \mathrm{~b}: \mathrm{P} 1.10$ & $153(1)$ \\
\hline \multirow[t]{3}{*}{ D (10) } & $\mathrm{C}: 4: \mathrm{P} 1.4$ (1) & \\
\hline & $\mathrm{C}: 4: \mathrm{P} 1.7(1)$ & $1031(1)$ \\
\hline & C:NT:NST (8) & 1031 (2) and 1032 (1) \\
\hline \multirow[t]{3}{*}{ E (3) } & $\mathrm{C}: 14: \mathrm{P} 1.7,1$ (1) & $1034(1)$ \\
\hline & C:14:P1.7(1) & 1034 (1) \\
\hline & C:2a:P1.5,2 (1) & 1033 (1) \\
\hline $\mathrm{F}(1)$ & C:4:P1.1 (1) & 206 (1) \\
\hline G (1) & C:NT:P1.15 (1) & $1030(1)$ \\
\hline $\mathrm{H}(1)$ & C:21:P1.1 (1) & 1029 (1) \\
\hline I (1) & C:NT:P1.5,2 (1) & $60(1)$ \\
\hline $\mathrm{J}(1)$ & $\mathrm{C}: 21: \mathrm{P} 1.15$ (1) & 467 (1) \\
\hline K (1) & C:NT:P1.1 (1) & $103(1)$ \\
\hline L (1) & C:4:NST (1) & $461(1)$ \\
\hline M (1) & $\mathrm{C}: 4,21: \mathrm{P} 1.5$ (1) & 1035 (1) \\
\hline N (1) & $\mathrm{C}: 15: \mathrm{P} 1.7,16$ (1) & $32(1)$ \\
\hline
\end{tabular}

${ }^{*}$ Corresponds with pattern 2723

Table 3. Novel STs found among Belgian serogroup C strains

\begin{tabular}{|c|c|c|c|c|c|c|c|c|}
\hline \multirow[b]{2}{*}{ Phenotype } & \multirow[b]{2}{*}{ ST number } & \multicolumn{7}{|c|}{ MLST allele number } \\
\hline & & $a b c Z$ & $a d k$ & $\operatorname{aroE}$ & fumC & $g d h$ & $p d h C$ & pgm \\
\hline $\mathrm{C}: 2 \mathrm{a}: \mathrm{NST}$ & 1025 & 2 & 3 & 4 & 3 & 8 & 4 & 2 \\
\hline $\mathrm{C}: 2 \mathrm{a}: \mathrm{P} 1.5,2$ & 1026 & 2 & 3 & 4 & 3 & 8 & 4 & 7 \\
\hline $\mathrm{C}: 2 \mathrm{a}: \mathrm{P} 1.5$ & 1027 & 2 & 3 & 4 & 55 & 8 & 4 & 6 \\
\hline C:NT:NST & 1028 & 3 & 6 & 9 & 2 & 9 & 6 & 9 \\
\hline $\mathrm{C}: 21: \mathrm{P} 1.1$ & 1029 & 6 & 6 & 9 & 21 & 9 & 73 & 9 \\
\hline $\mathrm{C}: \mathrm{NT}: \mathrm{P} 1.15$ & 1030 & 8 & 5 & 12 & 21 & 3 & 22 & 7 \\
\hline C:NT:NST; C:4:P1.7 & 1031 & 13 & 5 & 15 & 9 & 3 & 8 & 18 \\
\hline $\mathrm{C}: \mathrm{NT}: \mathrm{NST}$ & 1032 & 13 & 5 & 27 & 9 & 3 & 8 & 18 \\
\hline $\mathrm{C}: 2 \mathrm{a}: \mathrm{P} 1.5,2$ & 1033 & 14 & 2 & 120 & 9 & 3 & 8 & 18 \\
\hline $\mathrm{C}: 14: \mathrm{P} 1.7,1 ; \mathrm{C}: 14: \mathrm{P} 1.7$ & 1034 & 14 & 5 & 120 & 9 & 3 & 8 & 18 \\
\hline $\mathrm{C}: 4,21: \mathrm{P} 1.5$ & 1035 & 25 & 5 & 4 & 17 & 21 & 13 & 9 \\
\hline
\end{tabular}

serotype and sero-subtype, as well as in their genotypes. This is further demonstrated by the fact that the lineage III strains isolated in the Netherlands in the early 1980 s were B:4:P1.4 and belonged to the same clone, ET-24. However, after 1984 other clones appeared within the lineage, also with different serotypes and sero-subtypes [7]. In the 1990s seven new ETs of lineage III were found in Belgium, that had not previously been encountered in the Netherlands [1]. In the present study these clones were found to be still further diversified, as can be deduced from the PCRtyping data. Thus, the longer clones are prevalent in a population, the more heterogeneous they become in phenotype and genotype. Finally, their relationships become so obscured that they may no longer be recognisable as belonging to the ancestral clone.

From 1997 a clonal replacement started to take place in Belgium. The number of serogroup B strains gradually decreased, which was associated with an increase in the number of serogroup $\mathrm{C}$ strains. Their prevalence rose from $7.0 \%$ in 1996 to $20.8 \%$ in 1998 . N. meningitidis of serogroup $\mathrm{C}$ are associated with a higher case fatality rate than cases of serogroup $B$ infection. The most prevalent serotype was $\mathrm{C}: 2 \mathrm{~b}: \mathrm{P} 1.5,2$, accounting for $28 \%$ of the serogroup $\mathrm{C}$ strains. It is noteworthy 
that $\mathrm{C}: 2 \mathrm{~b}: \mathrm{P} 1.5,2$ strains are not new in Europe and predominated in Scotland in the 1980s [8]. Currently, strains of this phenotype are most prevalent in the southern part of Europe. In 1993, they caused an increase in the incidence of meningococcal disease in Spain, and in 1996, they accounted for $65 \%$ of the serogroup C strains in Spain [9]. Strains of phenotype $\mathrm{C}: 2 \mathrm{~b}: \mathrm{P} 1.5,2$ have often been shown to belong to meningococcal cluster $\mathrm{A} 4$, as did the majority of the $\mathrm{C}: 2 \mathrm{~b}$ isolates analysed here. This same clone complex was predominant in Greece in the early 1990s, but was associated with serogroup B polysaccharide [10], as it was in several European countries in the 1970s [5]. The 87 serogroup $C$ strains were all investigated by D8635primed PCR and PFGE, and a selection of 30 strains was also investigated by MLST. These three genotyping techniques provide estimates of similarity between isolates by sampling many unlinked genetic regions of the chromosome and are thus more reliable than typing methods that target single genes. The MLST data confirmed that the $\mathrm{C}: 2 \mathrm{~b}: \mathrm{P} 1.5,2$ strains indeed belonged to cluster A4. Strains of phenotype C:2a:P1.5,2, which was the second most important phenotype, were related to the globally distributed ET-37 complex.

When the discriminatory abilities of the different genotyping methods were compared, it was found that D8635-primed PCR was the least and PFGE the most discriminatory method. Indeed, strains with PCRpatterns A-E could be further subdivided by MLST. The STs could be further subdivided by PFGE. There was one exception where two strains with the same PFGE pattern showed differing STs. In comparison with PFGE fingerprint data, the MLST data were more readily interpreted and can easily be compared with data obtained in other studies. Consequently, MLST is becoming the reference method for $N$. meningitidis typing.

In conclusion, the incidence of meningococcal disease is still increasing in Belgium. This could be attributed to both the further expansion of the epidemic clone of lineage III and to the introduction of phenotype $\mathrm{C}: 2 \mathrm{~b}: \mathrm{P} 1.2,5$ strains of cluster A4 in the Belgian population. Further, this study illustrates the added value of genotyping in interpreting the epidemiology of meningococcal disease.

\section{References}

1. Van Looveren $\mathrm{M}$, Vandamme $\mathrm{P}$, Hauchecorne $\mathrm{M}$ et al. Molecular epidemiology of recent Belgian isolates of Neisseria meningitidis serogroup B. J Clin Microbiol 1998; 36: $2828-2834$.

2. Caugant DA, Bol P, Høiby EA, Zanen HC, Frøholm LO. Clones of serogroup B Neisseria meningitidis causing systemic disease in the Netherlands, 1958-1986. J Infect Dis 1990; 162: $867-874$.

3. Van Looveren $M$, Carion $F$, Vandamme $P$, Goossens $H$. Surveillance of meningococcal infections in Belgium. Clin Microbiol Infect 1998; 4: 224-228.

4. Tenover FC, Arbeit RD, Goering RV et al. Interpreting chromosomal DNA restriction patterns produced by pulsedfield gel electrophoresis: criteria for bacterial strain typing. J Clin Microbiol 1995; 33: 2233-2239.

5. Caugant DA. Population genetics and molecular epidemiology of Neisseria meningitidis. APMIS 1998; 106: 505-525.

6. Maiden MCJ, Bygraves JA, Feil E et al. Multilocus sequence typing: a portable approach to the identification of clones within populations of pathogenic microorganisms. Proc Natl Acad Sci USA 1998; 95: 3140-3145.

7. Scholten RJPM, Poolman JT, Valkenburg HA, Bijlmer HA, Dankert J, Caugant DA. Phenotypic and genotypic changes in a new clone complex of Neisseria meningitidis causing disease in the Netherlands, 1958-1990. J Infect Dis 1994; 169: 673-676.

8. Hubert B, Caugant DA. Recent changes in meningococcal disease in Europe. Eurosurveillance 1997; 2: 69-71.

9. Berrón E, De La Fuente L, Martín E, Vázquez JA. Increasing incidence of meningococcal disease in Spain associated with a new variant of serogroup C. Eur J Clin Microbiol Infect Dis 1998; 17: 85-89.

10. Tzanakaki G, Blackwell CC, Kremastinou J, Weir DM, Mentis A, Fallon RJ. Serogroups, serotypes and subtypes of Neisseria meningitidis isolated from patients and carriers in Greece. J Med Microbiol 1993; 38: 19-22. 